\title{
miRNA-556-3p promotes human bladder cancer proliferation, migration and invasion by negatively regulating DAB2IP expression
}

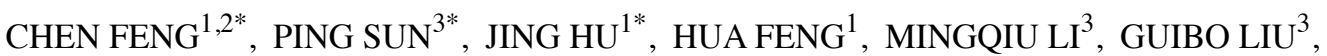 \\ YANMING PAN $^{1}$, YING FENG $^{4}$, YONGLIANG XU ${ }^{3}$, KEJIAN FENG $^{3}$ and YUKUAN FENG ${ }^{1,3}$ \\ ${ }^{1}$ Key Laboratory of Tumor Prevention and Treatment (Heilongjiang Higher Education Institutions), \\ Mudanjiang Medical University, Mudanjiang, Heilongjiang; ${ }^{2}$ Department of Bone Surgery, Hongqi Hospital \\ of Mudanjiang Medical University, Mudanjiang, Heilongjiang; ${ }^{3}$ School of Basic Medical Science, \\ Mudanjiang Medical University, Mudanjiang, Heilongjiang; ${ }^{4}$ Department of Neurology, \\ The Second Affiliated Hospital of Mudanjiang Medical University, Mudanjiang, Heilongjiang, P.R. China
}

Received November 9, 2016; Accepted April 10, 2017

DOI: $10.3892 /$ ijo.2017.3969

\begin{abstract}
MicroRNAs (miRNAs) play critical roles in tumorigenesis and metastasis by negatively regulating gene expression through complementary binding to the 3'-untranslated region of target mRNAs. The role of miRNAs in expression of the tumor suppressor DAB2IP in bladder cancer (BC) remains unknown. The aim of the present study was to identify miRNAs targeting DAB2IP and determine their expression and function in BC. We predicted candidate miRNAs targeting DAB2IP using TargetScan software. Dual-luciferase reporter assays confirmed that miRNA-556-3p directly regulated DAB2IP expression. Quantitative RT-PCR and RNase protection assays showed that endogenous miRNA-556-3p expression was significantly upregulated in clinical samples of $\mathrm{BC}$ patients and $\mathrm{BC}$ cell lines and western blot analysis indicated that DAB2IP expression in $\mathrm{BC}$ tissues and $\mathrm{BC}$ cell lines was concurrently downregulated. Gain or loss of function studies showed that upregulation of miRNA-556-3p promoted proliferation, invasion, migration and colony formation of $\mathrm{BC}$ cells, whereas downregulation resulted in opposite effects. Importantly, restoration of DAB2IP expression rescued the effects induced by miRNA-556-3p. Overexpression of miRNA-556-3p in BC
\end{abstract}

Correspondence to: Professor Yukuan Feng, Key Laboratory of Tumor Prevention and Treatment, Mudanjiang Medical University, 3 Tongxiang Street, Mudanjiang, Heilongjiang 157011, P.R. China E-mail: fengyukuan@163.com

Professor Kejian Feng, School of Basic Medical Science, Mudanjiang Medical University, 3 Tongxiang Street, Mudanjiang, Heilongjiang 157011, P.R. China

E-mail: fkj88812003@163.com

*Contributed equally

Key words: microRNA, bladder cancer, miRNA-556-3p, DAB2IP cells not only decreased DAB2IP expression, but also markedly increased Ras GTPase activity and ERK1/2 phosphorylation level. These findings suggest that DAB2IP is a direct target of miRNA-556-3p, and endogenous miRNA-556-3p expression shows inverse correlation with simultaneous DAB2IP expression in BC tissues and cells. miRNA-556-3p functions as a tumor promoter in tumorigenesis and metastasis of $\mathrm{BC}$ by targeting DAB2IP. Moreover, miRNA-556-3p-mediated DAB2IP suppression plays an oncogenic role by partial activation of the Ras-ERK pathway.

\section{Introduction}

Bladder cancer (BC) is among the most prevalent cancers worldwide and recently appears to be increasing in incidence. It is reported that there are $\sim 261,000$ new cases and 115,000 deaths from $\mathrm{BC}$ each year $(1,2)$. BC is classified into two major groups with different biological properties: non-muscle invasive and muscle-invasive bladder cancers (3). Most cases of BC (75-80\%) are diagnosed as non-muscle invasive tumors, which have high recurrence rates of $50-70 \%$ (4). The remainder $(\sim 15 \%)$ are high-grade muscle-invasive tumors that can rapidly progress to metastasis and death (5). Despite existing multiapproach treatment regimens, including radical cystectomy, bladder-sparing therapy with transurethral resection, chemotherapy and radiotherapy, the median overall survival for metastatic BC is merely 13-15 months (6). Thus, there is an urgent need to gain further insight into the molecular mechanisms of tumorigenesis and metastasis of $\mathrm{BC}$ and find novel therapeutic strategies to improve the outcome of patients with $\mathrm{BC}$.

DAB2IP acts as a tumor suppressor and is often downregulated by epigenetic modification in many aggressive types of cancer including prostate, breast, advanced lung and pancreatic cancer (7-12). For example, DAB2IP-deficient prostate cancer cells show great proliferative potential and become resistant to stress-induced apoptosis and loss of DAB2IP expression in prostate epithelial cells results in epithelial-mesenchymal 
transition, a central step in tumor metastasis $(13,14)$. In pancreatic cancer, decreased DAB2IP expression is associated with clinical stage, development and infiltration of pancreatic cancer (12). Compared with widespread reports in other cancers, only few studies have described dysregulated DAB2IP expression and its correlation with disease outcome in BC $(15,16)$ and the tumor suppressive role of DAB2IP in BC has not been fully elucidated.

MicroRNAs (miRNAs), endogenous 19 to 22-nucleotide non-coding RNAs, negatively regulate gene expression through complementary binding to the 3'-untranslated region (3'-UTR) of target mRNAs, which can lead to blockage of translation and degradation of the mRNA (16-18). miRNAs can affect various biological behaviors of tumors, such as proliferation, invasion, apoptosis and metastasis. Increasing evidence has demonstrated that miRNAs act as oncogenes or tumor suppressors in many human cancers, including BC (19). Recently, some dysregulated miRNAs have been identified to regulate tumorigenesis and metastasis of $\mathrm{BC}(20-24)$. For instance, upregulated miRNA-19a expression in BC tissues can significantly promote growth of BC cells by targeting PTEN (25) and miRNA-137, which is identified as a regulator of the tumor suppressor gene $P A Q R 3$, functions as an oncogene by promoting proliferation, migration and invasion of BC cells (26). Moreover, some miRNAs (miRNA-143, miRNA-490-5p, miRNA-576-3p, miRNA-204 and miRNA-145) have been proved to function as tumor suppressors by inhibiting proliferation of BC (27-31). However, few studies have investigated which miRNAs directly regulate DAB2IP expression in BC. Furthermore, the pattern and regulatory mechanism of interactions between miRNAs and DAB2IP in BC cells remain unknown.

In the present study, we provide the first demonstration that DAB2IP is a direct target of a new microRNA (miRNA-556-3p), and show that endogenous miRNA-556-3p expression negatively correlates with simultaneous DAB2IP expression in $\mathrm{BC}$ tissues and cells. Functional analysis showed that ectopic expression of miRNA-556-3p could promote proliferation, invasion, migration and colony formation by targeting DAB2IP. Further investigation verified that the tumor promotion effect driven by miRNA-556-3p in BC cells is partially dependent on activation of the Ras-ERK pathway.

\section{Materials and methods}

Human BC tissue and plasma samples. Human BC tissue samples were obtained from 30 patients with BC who underwent surgery at Hongqi Hospital (Mudanjiang, China) from 2011 to 2013. Patients who underwent preoperative chemotherapy and radiotherapy were excluded. In addition, 30 peritumoral tissues adjacent to the tumor margin were used as controls. All samples were immediately snap-frozen in liquid nitrogen and stored at $-80^{\circ} \mathrm{C}$ until RNA and protein extraction. Blood samples were collected from bladder cancer patients and from volunteers as controls. All blood samples were collected in EDTA tubes and processed within $1 \mathrm{~h}$ of collection. Blood samples were centrifuged to obtain plasma, which was stored at $-80^{\circ} \mathrm{C}$ until RNA extraction. All clinical samples were collected after obtaining informed consent from participants and with approval from the ethics committee of Hongqi Hospital.
Cell culture. Five BC cell lines (BIU-87, T24, 5637, J82 and EJ), a non-tumorigenic bladder cell line (SV-HUC-1) and the viral packaging cell line (293T) were purchased from the Institutes of Biochemistry and Cell Biology (Shanghai, China) and originated from the American Type Culture Collection (ATCC; Manassas, VA, USA). 293T and SV-HUC-1 cells were cultured in Dulbecco's modified Eagle's medium (DMEM; Invitrogen, Carlsbad, CA, USA) and other BC cells were cultured in RPMI-1640 medium. The media were supplemented with $10 \%$ fetal bovine serum (FBS; Invitrogen) and $1 \%$ penicillin-streptomycin. Cells were adherent and passaged by trypsin digestion, and all cells were maintained at $37^{\circ} \mathrm{C}$ in a humidified $5 \% \mathrm{CO}_{2}$ incubator.

Quantitative reverse transcriptase-polymerase chain reaction ( $q R T-P C R)$. Total RNA was extracted from plasma and tissues of BC patients using TRIzol reagent (Invitrogen). Complementary DNA was synthesized from total RNA using a M-MLV reverse transcription kit (Takara Bio, Dalian, China) with the specific primers U6 snRNA (NM_001101. 3; 5'-TACC TTGCGAAGTGCTTAAAC-3') and miRNA-556-3p (5'-GTC GTATCCAGTGCGTGTCGTGGAGTCGGCAATTGCACT GGATACGACAAAGA-3'). cDNA samples were used as templates for amplification reactions carried out in a PCR Thermal Cycler Dice Real-Time system with the SYBR ${ }^{\circledR}$ PrimeScript PCR kit (Takara Bio) following our previously described procedure (32). The expression of miR-556-3p was analyzed with the $2^{-\triangle \Delta C T}$ method. For each sample, triplicate determinations were performed and mean values were adopted for further calculations. All values were normalized to an endogenous U6 control. The PCR primers for mature miRNA556-3p or U6 were designed as follows: miRNA-556-3p forward, 5'-ATATTACCATTAGCTCATCTTT-3' and reverse, 5'-GTCGTATCCAGTGCGTGTCGTG-3'; U6 forward, 5'-GT GCTCGCTTCGGCAGCACAT-3' and reverse, 5'-TACCTTG CGAAGTGCTTAAAC-3'.

RNase protection assay (Rpa). Mature miRNA-556-3p from bladder cancer cells was detected by Rpa as previously described (33). Briefly, total mRNA was extracted from BC cells by the TRIzol method (Invitrogen). ${ }^{32} \mathrm{P}$-labeled antisense RNA probe (5'-AAAGAUGAGCUAAUGGUAAUAU-3') complementary to miR-556-3p was used in RNase protection assays. The RNA probe was prepared using a mirVana miRNA Probe Construction kit (AM1550; Invitrogen) following the manufacturer's protocol. Total RNA $(5 \mu \mathrm{g})$ was hybridized with the probe at $52^{\circ} \mathrm{C}$ for $16 \mathrm{~h}$. RNases A/T1 were added and the mixture was incubated at $37^{\circ} \mathrm{C}$ for $30 \mathrm{~min}$. The remaining RNA was precipitated by ethanol after heat inactivation and separated by $15 \%$ denaturing PAGE. The probes were visualized by autoradiography. Endogenous U6 was used as the internal normalization control.

Western blot analysis. Protein extractions were prepared using a previously described procedure (32) and western blot analysis was performed in triplicate experiments. Protein lysates were subjected to $11 \%$ SDS-PAGE and proteins were electrotransferred to polyvinylidene fluoride membranes (Millipore, Billerica, MA, USA). Membranes were incubated with 5\% non-fat dry milk in TBS and probed with anti-DAB2IP 
(1:500), anti-Ras (1:200), anti-phosphorylated-ERK1/2 (1:400), anti-ERK1/2(1:600) and anti-GAPDH (1:1,200; Abcam, Cambridge, MA, USA) antibodies in TBST (0.1\% Tween-20 in TBS). Horseradish peroxidase-conjugated anti-rabbit (or mouse) IgG (Cell Signaling Technology, Danvers, MA, USA) was used for detection of immunoreactive proteins by chemiluminescence (Pierce, Rockford, IL, USA) and imaging with $\mathrm{X}$-ray film. GAPDH was used as an endogenous reference for normalization.

Cell proliferation assay. Cell proliferation assays were performed using the Cell Counting kit-8 assay (CCK-8; Dojindo Laboratories, Kumamoto, Japan) following the manufacturer's protocol. At $72 \mathrm{~h}$ after viral infection, BIU-87, 5637 and T2 4 cells that were uninfected or infected with LV-control, Lv-miRNA-556-3p, or Lv-miRNA-556-3p-inhibition were seeded into 96 -well plates at $1 \times 10^{3}$ cells/well and grown for 24 , 48 and $72 \mathrm{~h}$. At the end of the incubation, $10 \mu \mathrm{l}$ of CCK-8 solution was added to each well and samples were incubated for $4 \mathrm{~h}$ at $37^{\circ} \mathrm{C}$. Absorbance at $490 \mathrm{~nm}$ was read on a microplate reader (Multiskan Spectrum; Thermo Fisher Scientific, Waltham, MA, USA). All experiments were performed in triplicate experiments and the average of the results was calculated.

Colony formation assay. A total of $0.5 \times 10^{3} \mathrm{~T} 24$ cells $(72 \mathrm{~h}$ after viral infection) were seeded into 6 -well plates and cultured for 10 days. Media were replaced with fresh media on days 3 and 6. Following incubation, colonies were washed with phosphate-buffered saline (PBS), fixed for $5 \mathrm{~min}$ with $4 \%$ paraformaldehyde and stained with $0.1 \%$ crystal violet for $30 \mathrm{sec}$. The colony formation assay was repeated three times with duplicate wells.

Wound healing assay. A total of $1 \times 10^{5} 5637$ cells ( $72 \mathrm{~h}$ after viral infection) were seeded in 6-well plates and cultured until they reached confluence. Confluent monolayer cells were scratched with a 200- $\mu 1$ pipette tip (Axygen Scientific, Inc., Union City, CA, USA) and washed three times with PBS to remove cell debris and cells in suspension. Fresh serum-free medium was added and the cells were allowed to close the wound for $48 \mathrm{~h}$ under normal conditions. Images were taken at the same position of the wound with a computer-assisted microscope (Nikon Corp., Tokyo, Japan) at 24 and $48 \mathrm{~h}$.

Cell invasion assay. Invasion of BIU-87 cells (72 h after viral infection) was determined using the QCM $^{\text {тм }}$ 24-well Fluorimetric Cell Invasion Assay kit (ECM554; Chemicon, Temecula, CA, USA) according to the manufacturer's instructions. The kit uses an insert polycarbonate membrane with $8-\mu \mathrm{m}$ pore size. The insert was coated with a thin layer of ECMatrix $^{\mathrm{TM}}$ that occluded the membrane pores and blocked migration of non-invasive cells. Culture medium $(500 \mu \mathrm{l})$ supplemented with $10 \%$ FBS was used as a chemoattractant. Cells that migrated and invaded the underside of the membrane were fixed in $4 \%$ paraformaldehyde. The invaded cells were stained with DAPI.

Construction of recombinant expression vectors. Human genomic DNA was extracted from BIU-87 cells and used for amplification of the template for the precursor sequence of
miRNA-556-3p. The primers used were 5'-GGAATTCTTAG AGCTGTAAAACAATTACT-3' and 5'-CGGGATCCCCT ATACTCAAGTCTAACATTC-3'. The PCR product was digested using EcoRI and $B a m \mathrm{HI}$, ligated into a linear pCDHEF1-GFP vector (System Biosciences, Palo Alto, CA, USA) and transformed into Top10 competent cells (Takara Bio). The resultant vector was called pcDH-miRNA-556-3p.

An inhibition sequence that complementarily binds to miRNA-556-3p was chosen. The oligonucleotide templates of three tandem inhibition sequences were chemically synthesized and cloned into linear pcDH vector (System Biosciences) obtained by digestion by BamHI and EcoRI and purification by agarose gel electrophoresis. The recombinant vector was named pcDH-inhibition-miRNA-556-3p.

The CDS sequence of human DAB2IP (NM_032552.3) was amplified using the primers 5'-CCCAAGCTTGCCACC ATGGAGCCCGACTCCCTT-3' and 5'-CGGAATTCCTAAT GCATACTCTCTTTC-3', which contain a HindIII restriction site and Kozak sequence and a BamHI cutting site, respectively. cDNA was prepared by reverse transcription of RNA isolated from 293T cells. The PCR product was digested and cloned into a pcDH-CMV lentiviral expression vector. The final recombinant vector was named pcDH-DAB2IP.

The products of the vectors were confirmed by DNA sequencing. Endotoxin-free DNA was prepared in all cases.

Lentivirus packaging and lentiviral infection of cells. All recombinant lentivirus vectors ( $\mathrm{pcDH}-\mathrm{miRNA}-556-3 \mathrm{p}, \mathrm{pcDH}-$ DAB2IP and pcDH-miRNA-556-3p-inhibition) and lentiviral packaging plasmids (System Biosciences) were cotransfected into 293T packaging cells using Lipofectamine 2000 (Invitrogen) according to the manufacturer's instruction. At $48 \mathrm{~h}$ after transfection, the supernatant was harvested, cleared by centrifugation at $5,000 \mathrm{x} \mathrm{g}$ at $4^{\circ} \mathrm{C}$ for $5 \mathrm{~min}$ and passed through a $0.45-\mu \mathrm{m}$ PVDF membrane (Millipore). The titer of virus was determined by gradient dilution. The packaged lentiviruses were named Lv-miRNA-556-3p, Lv-DAB2IP and Lv-miRNA-556-3p-inhibition.

Suspensions of BC cell lines BIU-87, 5637 and T24 in logarithmic phase were prepared by trypsin digestion and the number of viable cells was counted with a hemocytometer after trypan blue staining. Cells were collected by centrifugation at $1,000 \mathrm{x} g$ and resuspended in complete RPMI-1640 medium to a concentration of $1 \times 10^{6}$ cells $/ \mathrm{ml}$. Cells were seeded on 6 -well plates at $2 \mathrm{ml} /$ well and cultured overnight under normal conditions. The medium was replaced with $2-\mathrm{ml}$ complete medium containing $10 \mu \mathrm{l}$ of viral solution. The infection efficiency was observed using the fluorescent marker $72 \mathrm{~h}$ after infection, and the levels of miRNA-556-3p and DAB2IP in cells were detected by qRT-PCR or western blotting, respectively. The infected cells were reseeded and cultured under normal conditions for a further $72 \mathrm{~h}$ before use in assays for proliferation, colony formation, wound healing and invasion. At $72 \mathrm{~h}$ after infection, the cells were collected and total protein was extracted for detection of Ras levels and ERK1/2 phosphorylation level by western blotting.

3'-TUR luciferase reporter assay. The 3'-untranslated region (253 bp) of human DAB2IP was amplified from cDNA obtained by reverse transcription of total RNA of $293 \mathrm{~T}$ 
Table I. Ten candidate miRNAs were detected in plasma samples from 30 BC patients and 30 healthy volunteers by qRT-PCR.

\begin{tabular}{|c|c|c|c|}
\hline $\begin{array}{l}\text { Candidate miRNAs } \\
\text { target to DAB2IP }\end{array}$ & PCR primers for candidate miRNAs & Result & P-value \\
\hline \multirow[t]{2}{*}{ hsa-miR-4469 } & Forward primer: GCTCCCTCTAGGGTCGCTCGGA & & \\
\hline & Reverse primer: TCGTATCCAGTGCGTGTCGTG & Yes & $\mathrm{P}>0.05$ \\
\hline \multirow[t]{2}{*}{ hsa-miR-4725-5p } & Forward primer: AGACCCTGCAGCCTTCCCACC & & \\
\hline & Reverse primer: GTCGTATCCAGTGCGTGTCGTG & Yes & $\mathrm{P}<0.05^{\mathrm{a}}$ \\
\hline \multirow[t]{2}{*}{ hsa-miR-3119 } & Forward primer: TGGCTTTTAACTTTGATGGC & & \\
\hline & Reverse primer: GTCGTATCCAGTGCGTGTCGTG & Yes & $P>0.05$ \\
\hline \multirow[t]{2}{*}{ hsa-miR-25 } & Forward primer: CATTGCACTTGTCTCGGTCTGA & & \\
\hline & Reverse primer: GTCGTATCCAGTGCGTGTCGTG & No & - \\
\hline \multirow[t]{2}{*}{ hsa-miR-556-3p } & Forward primer: ATATTACCATTAGCTCATCTTT & & \\
\hline & Reverse primer: GTCGTATCCAGTGCGTGTCGTG & Yes & $\mathrm{P}<0.05^{\mathrm{a}}$ \\
\hline \multirow[t]{2}{*}{ hsa-miR-4691-3p } & Forward primer: CCAGCCACGGACTGAGAGTGCAT & & \\
\hline & Reverse primer: GTCGTATCCAGTGCGTGTCGTG & Yes & $\mathrm{P}<0.05^{\mathrm{a}}$ \\
\hline \multirow[t]{2}{*}{ hsa-miR-518a-5p } & Forward primer: CTGCAAAGGGAAGCCCTTTC & & \\
\hline & Reverse primer: GTCGTATCCAGTGCGTGTCGTG & Yes & $\mathrm{P}>0.05$ \\
\hline \multirow[t]{2}{*}{ hsa-miR-504 } & Forward primer: AGACCCTGGTCTGCACTCTATC & & \\
\hline & Reverse primer: GTCGTATCCAGTGCGTGTCGTG & No & - \\
\hline \multirow[t]{2}{*}{ hsa-miR-4735-5p } & Forward primer: CCTAATTTGAACACCTTCGGTA & & \\
\hline & Reverse primer:GTCGTATCCAGTGCGTGTCGTG & Yes & $\mathrm{P}>0.05$ \\
\hline \multirow[t]{2}{*}{ hsa-miR-576-5p } & Forward primer: ATTCTAATTTCTCCACGTCTTT & & \\
\hline & Reverse primer: GTCGTATCCAGTGCGTGTCGTG & Yes & $\mathrm{P}<0.05^{\mathrm{a}}$ \\
\hline
\end{tabular}

Result: the candidate miR could be detected in plasma samples (Yes); the candidate miR could not be detected in plasma samples (No); ${ }^{a} \mathrm{P}-\mathrm{value}$, differences between $\mathrm{BC}$ patients and healthy volunteers were analyzed and the differences were considered statistically significant at $\mathrm{P}<0.05$.

cells using the primers 5'-GCTCTAGAGAGCATCTGCC CCAGGTACACCT-3' and 5'-GCTCTAGAGAGCATCTG CCCCAGGTACACCT-3'. The amplification parameters were 32 cycles of denaturation at $95^{\circ} \mathrm{C}$ for $10 \mathrm{sec}$, annealing at $58^{\circ} \mathrm{C}$ for $30 \mathrm{sec}$ and extension at $72^{\circ} \mathrm{C}$ for $30 \mathrm{sec}$. The product was then digested with $\mathrm{XbaI}$ and inserted into the pGL3-promotor vector (Promega, Madison, WI, USA). The seed region was mutated by point mutagenesis from 5'-GTAATA-3' to 5'-ATAAGT-3'. The resulting vectors were named pGL-WT (wild-type)-DAB2IP and pGL-MT (mutated type)-DAB2IP. The pRL-TK vector (Promega) was used as an internal control. Luciferase reporter plasmid was cotransfected into 293 T cells with miRNA-556-3p mimics (5'-AUAUUACCAUU AGCUCATCUUUtt-3'), miRNA-556-3p inhibitor (5'-AAA GAUGAGCUAAUGGUAAUAUtt-3'), or negative control (NC, 5'-AGUCAUUACAUACUUCUCUAUUtt-3'). After $48 \mathrm{~h}$ of transfection, cells were harvested and assayed with the Dual-Luciferase assay kit (Promega) according to the manufacturer's protocol.

Ras GTPase activity assay. To investigate the effect of miRNA-556-3p on Ras GTPase activity through DAB2IP, we examined Ras GPTase activity in three cell lines (BIU-87, 5637 and T24) at $72 \mathrm{~h}$ after lentiviral infection strictly following the instructions of Ras GTPase ELISA kit (chemiluminescent) (ab134640; Abcam).
Statistical analysis. Statistical analysis was performed using the SPSS statistical software (16.0 for Windows). Experimental data were expressed as means \pm standard deviation (SD). Differences between groups were analyzed using the Student's $\mathrm{t}$-test and the one-way analysis of variance (ANOVA). All statistical tests performed were two-sided. Differences were considered statistically significant at $\mathrm{P}<0.05$. All experiments were performed at least three times to insure reproducibility of the results.

\section{Results}

DAB2IP expression inversely correlates with levels of candidate miRNAs targeting DAB2IP in BC tissues and BC cells. To search for candidate miRNAs that were differentially expressed in BC, we used TargetScan 6.1 to assess miRNAs complementary to the DAB2IP 3'-UTR. Two transcript variants of human DAB2IP mRNA (NM_032552.3 and NM_138709.2) contained 38 miRNAs with a 7-nucleotide seed match at different positions of the DAB2IP 3'-UTR. Of these, 10 miRNAs exhibited highly conserved target sites and 28 miRNAs had poorly conserved target sites in the 3'-UTR of DAB2IP (data not shown). The expression of 10 candidate miRNAs (exhibited highly conserved target sites) targeting DAB2IP was examined in plasma samples from $30 \mathrm{BC}$ patients and 30 healthy volunteers by qRT-PCR 
A
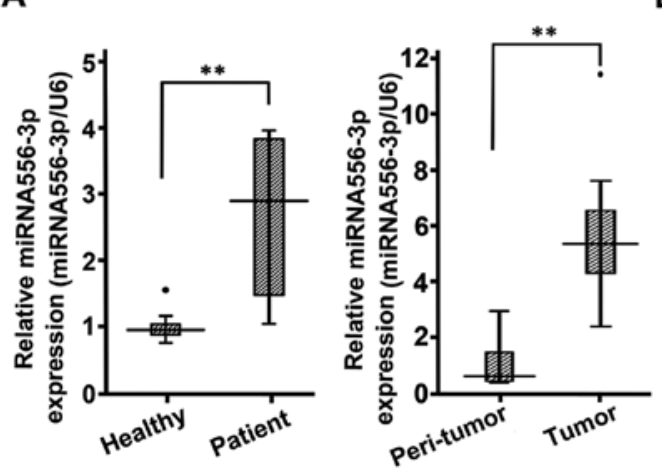

B

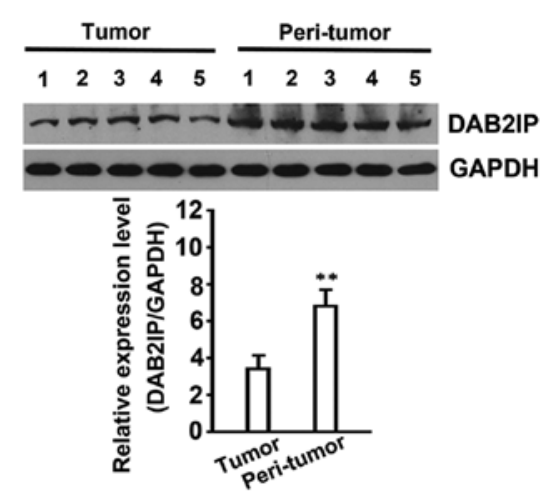

C
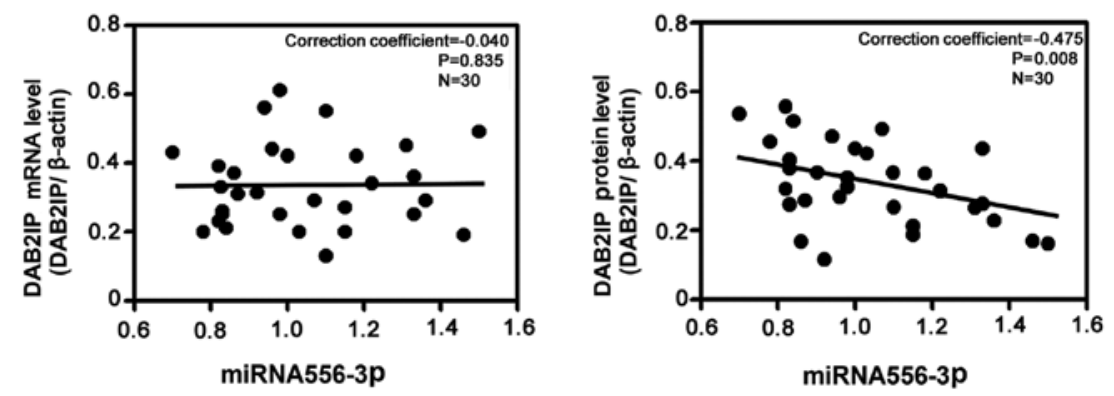

D
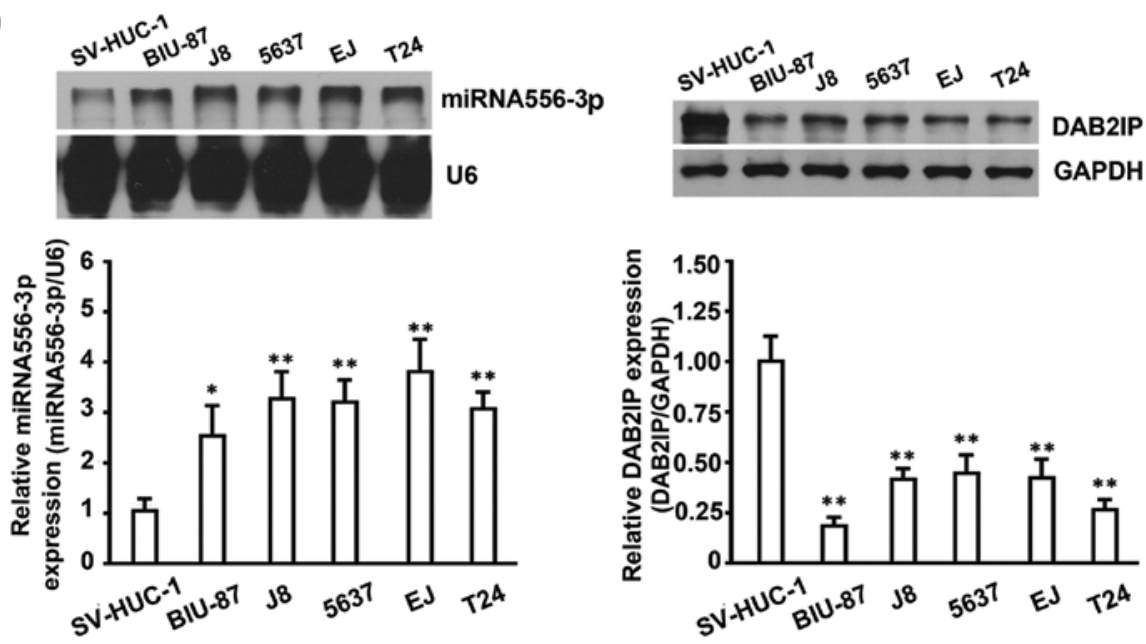

Figure 1. miRNA-556-3p is upregulated in the serum of bladder cancer patients, tumor tissues and tumor cell lines, which is inversely correlated with the DAB2IP expression in tumor tissues and tumor cell lines. (A) The expressions of miRNA-556-3p in the serum and tissues were measured using qRT-PCR. Left panel, plasma samples from 30 bladder cancer patients and 30 healthy volunteers; right panel, 30 paired bladder cancer tissues and adjacent peritumoral tissues. (B) DAB2IP in tumor tissues was downregulated compared to their paired peritumoral tissues. (C) Correlation analysis of DAB2IP protein/mRNA and miRNA-556 in tumor. Spearman analysis showed that miRNA-556-3p level was inversely correlated with DAB2IP protein but not DAB2IP mRNA. (D) The expression of miRNA-556-3p and DAB2IP in five bladder cancer cell lines (BIU-87, J8, 5637, EJ and T24) and non-tumorigenic bladder cell line (SV-HUC-1) were detected using Rpa and western blot analysis. The results represent data from at least three indepentent experiment expressed as mean $\pm \mathrm{SD}$. $\mathrm{P}<0.05$; ${ }^{* *} \mathrm{P}<0.01$.

(Table I). Of 10 candidate miRNAs, four candidate miRNAs (miRNA-4725-5p, miRNA-556-3p, miRNA-4691-3p and miRNA-576-5p) were significantly increased in BC patients compared with healthy volunteers. To further search for candidate miRNAs, the expression of 4 candidate miRNAs (miRNA-4725-5p, miRNA-556-3p, miRNA-4691-3p and miRNA-576-5p) targeting DAB2IP was examined in 30 $\mathrm{BC}$ tissues and adjacent peritumoral tissues. Compared to the expression of miRNA-4725-5p and miRNA-576-5p, the expression of miRNA-556-3p and miRNA-4691-3p was remarkable increased in $\mathrm{BC}$ tissues than those in peritumoral tissues, thus, we selected miRNA-556-3p and miRNA-4691-3p to perform luciferase reporter assays. The luciferase reporter assays showed that miRNA-556-3p overexpression could significantly reduce the activity of a luciferase reporter containing the DAB2IP 3'-UTR (results see below), but the miRNA-4691-3p could not serve as DAB2IP gene regulator (data not shown). As a result, we selected miRNA-556-3p for further experiments.

The results (Fig. 1A, left panel) showed that miRNA-556-3p in plasma samples from $30 \mathrm{BC}$ patients was differentially expressed compared with the control group (30 healthy volunteers; $\mathrm{P}<0.05)$. Subsequent analysis of the miRNA-556-3p level in 30 paired $\mathrm{BC}$ tissues and adjacent peritumoral tissues 


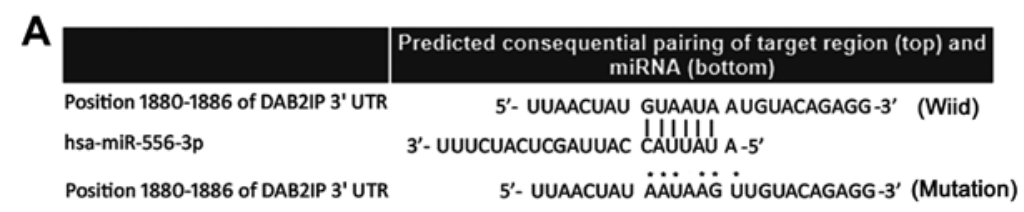

B

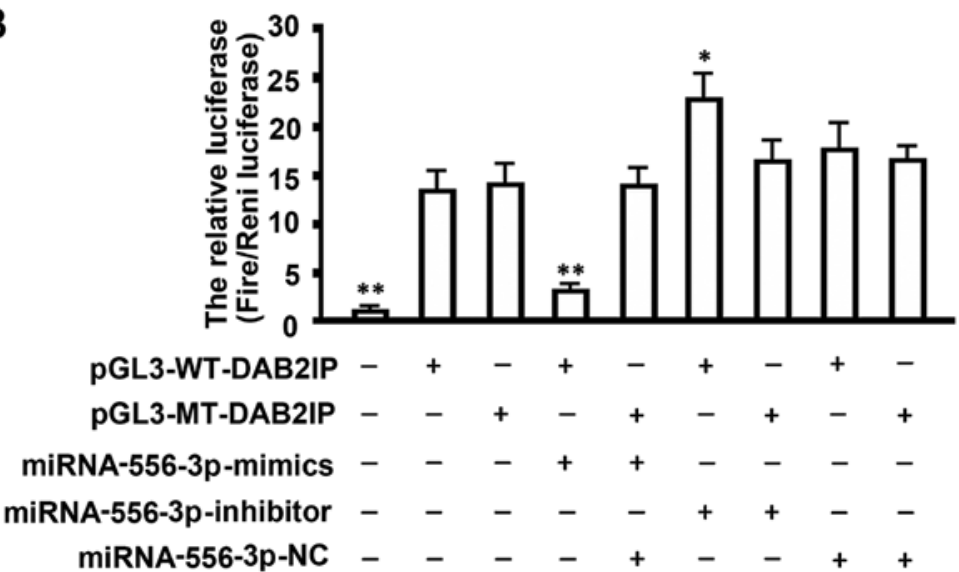

Figure 2. Verification of interaction between miRNA-556-3p and DAB2IP. (A) Predicted binding site of miRNA-556-3p in 3'-UTR of DAB2IP gene. (B) Effects of miRNA-556-3p on the expression of a luciferase cassette encoding the DAB2IP 3'-UTR. Cells (293) were transfected with pGL3-WT or pGL3-MT in the presence or absence of miRNA-556-3p-mimic or miRNA-556-3p-inhibitor. The histogram shows the relative firefly luciferase activity for the different experimental groups. Error bars represent standard deviation and data were obtained from at least three independent experiments. ${ }^{*} \mathrm{P}<0.05 ;{ }^{* *} \mathrm{P}<0.01$.

by qRT-PCR showed that the miRNA-556-3p level was significantly increased in BC tissues compared with controls (Fig. 1A, right panel). To confirm the association between miRNAs targeting DAB2IP and DAB2IP expression, we detected DAB2IP protein expression in $\mathrm{BC}$ tissues by western blotting. To show all results in the same membrane, we included paired samples from $\mathrm{BC}$ tissues and adjacent peritumoral tissues (Fig. 1B), respectively.

Correlation analysis of DAB2IP protein/mRNA and miRNA-556-3p in tumor was performed, and spearman analysis showed that in 30 tumor samples, miRNA-556-3p level was inversely correlated with DAB2IP protein (correction coefficient, $-0.475 ; \mathrm{P}=0.008$ ) but not DAB2IP mRNA (correction coefficient, $-0.040, \mathrm{P}=0.835$; Fig. 1C). As confirmed in other cancers, DAB2IP expression in BC tissues was significantly decreased compared with controls, indicating that DAB2IP expression inversely correlated with levels of miRNA-556-3p in BC tissues.

To verify whether endogenous DAB2IP expression in BC cells also correlated with miRNA-556-3p, the expression of miRNA-556-3p and DAB2IP in BC cells was detected by Rpa and western blot analysis, respectively. The results (Fig. 1D) confirmed that BC cell lines (BIU-87, T24, 5637, J82 and EJ) with high levels of miRNA-556-3p showed much lower DAB2IP expression than control cells (SV-HUC-1) with low levels of miRNA-556-3p but higher DAB2IP expression. Taken together, our results indicated that DAB2IP would be a direct target of miRNA-556-3p, and that endogenous miRNA-556-3p expression showed a negative correlation with simultaneous DAB2IP expression in $\mathrm{BC}$ cells.

Prediction of candidate miRNAs targeting DAB2IP by TargetScan and verification of the relationship between miRNA-556-3p and DAB2IP. Bioinformatic analysis (Fig. 2A) showed a seeding area of hsa-miRNA-556-3p in the 3'-UTR of the DAB2IP gene: 5'-GUAAUAA-3'. To determine whether miRNA-556-3p is a regulator of DAB2IP expression, we performed luciferase reporter assays in 293T cells. Luciferase reporter plasmids with wild-type or mutant sequence in the 3'-UTR of DAB2IP mRNA were cotransfected with miRNA556-3p mimics, inhibitor, or negative control (NC) into $293 \mathrm{~T}$ cells for $48 \mathrm{~h}$, followed by measurement of luciferase activity (Fig. 2B). Our results showed that cotransfection of miRNA-556-3p mimics significantly inhibited the activity of firefly luciferase reporter with wild-type 3'-UTR of DAB2IP, but not of those with the mutant 3'-UTR, whereas inhibition of miRNA-556-3p by miRNA-556-3p inhibitor exhibited opposite results (Fig. 2B).

Enhanced miRNA-556-3p expression promoted proliferation of BC cells. To investigate the effects of miRNA-556-3p in BC cells, BIU-87, 5637 and T24 cells were genetically engineered with Lv-miRNA-556-3p, Lv-miRNA-556-3p-inhibition, or Lv-Control. The pcDH-copGFP lentiviral vector carries a green fluorescent protein that allows measurement of transfection efficiency. More than $90 \%$ transfection efficiency was confirmed in these cells by fluorescent microscopy (Fig. 3A). After $72 \mathrm{~h}$ of transfection, multiple cellular RNA preparations were assayed for miR-556-3p expression by qRT-PCR (Fig. 3B). miRNA-556-3p expression level in Lv-miRNA-556-3p cells was significantly higher than that in untreated cells $(\mathrm{P}<0.05)$, whereas miRNA-556-3p expression was markedly inhibited in Lv-miRNA-556-3p-inhibition cells $(\mathrm{P}<0.05)$. There was no difference in miRNA-556-3p expression between Lv-NC cells and untreated cells $(\mathrm{P}>0.05)$. Next, we examined the effect of miRNA-556-3p on proliferation of BC cells in vitro by CCK-8 assay. As shown in Fig. 3C, miRNA-556-3p overexpression significantly increased the growth rate of BIU-87, 5637 and 
A

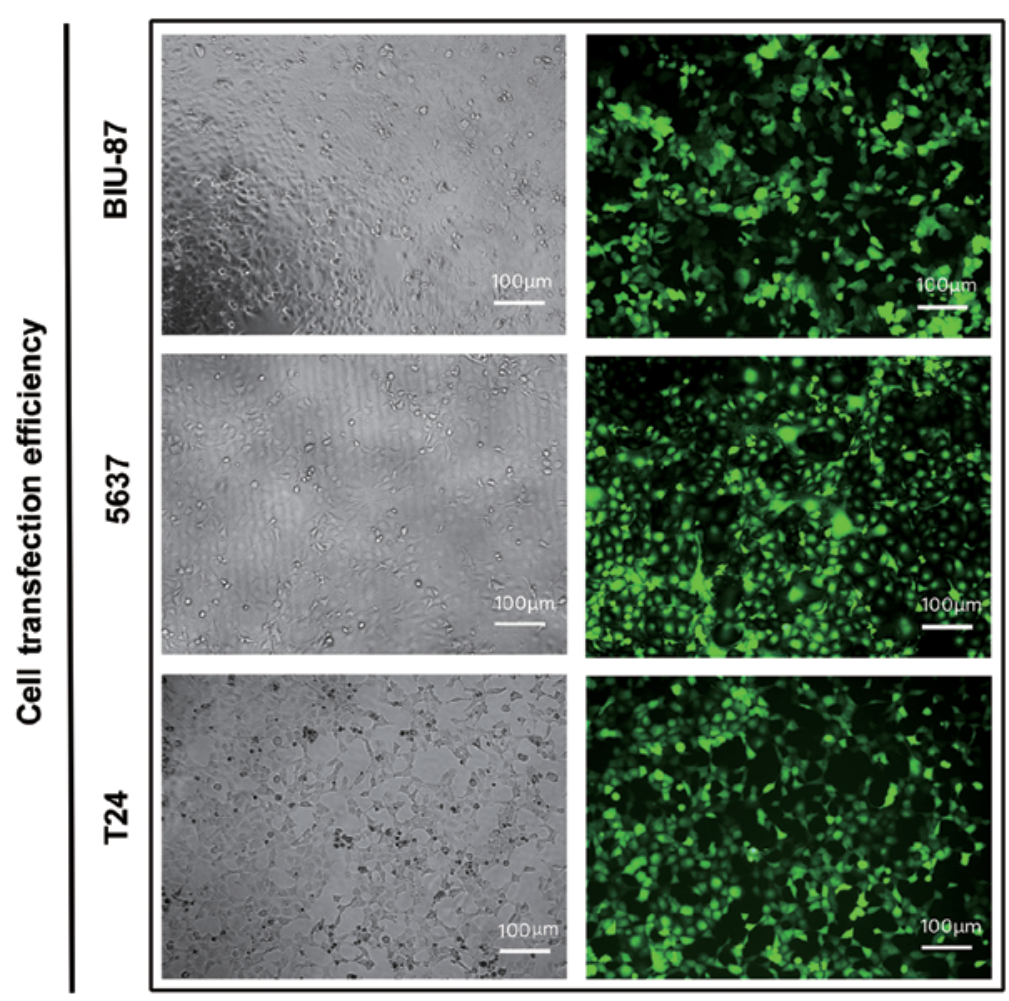

C

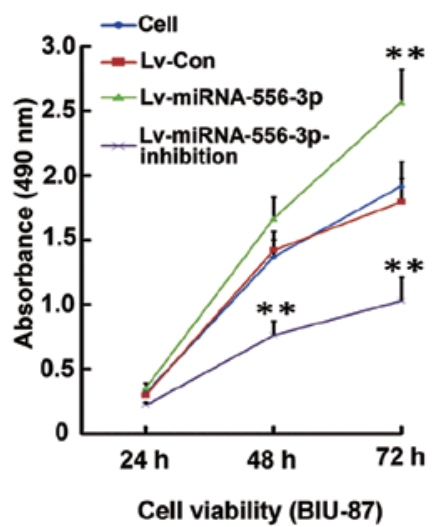

B
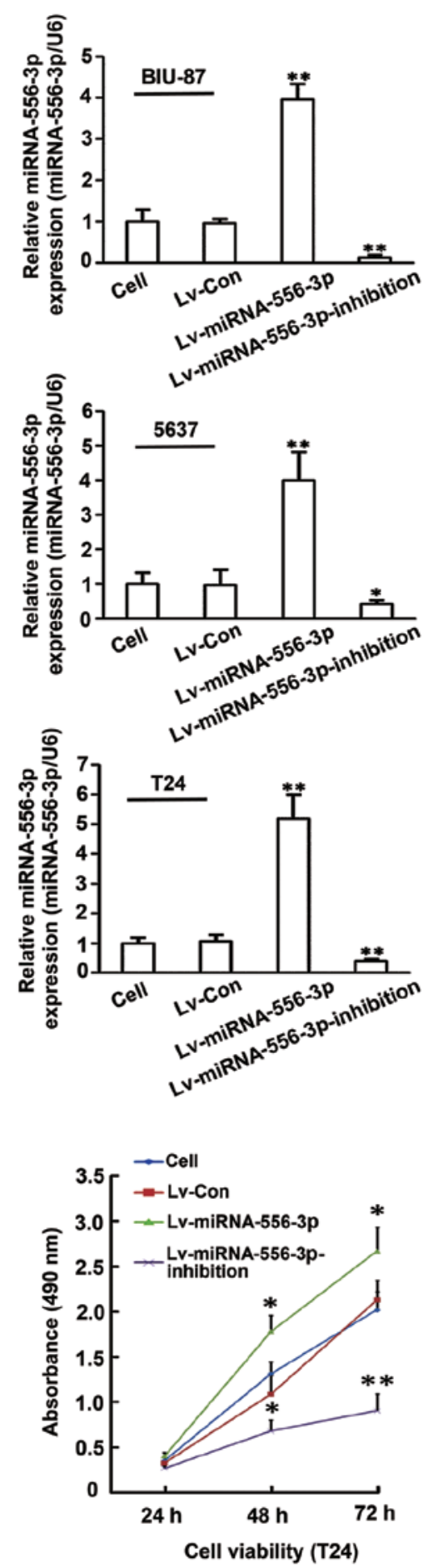

Figure 3. Effects of promotion of miRNA-556-3p overexpression on cellular proliferation in vitro BC cell lines. (A) Stable cell lines expressing Lv-miRNA-556-3p were examined by fluorescent microscopy. (B) miRNA-556-3p expression was measured by quantitative reverse transcriptase polymerase chain reaction (qRT-PCR) and U6 was used as internal control. (C) CCK-8 assay was performed to determine the proliferation of BIU-87, 5637 and T24 cells at 24, 48 and $72 \mathrm{~h}$ after transfection. The results represent data from at least three indepentent experiment expressed as mean $\pm \mathrm{SD}$. ${ }^{*} \mathrm{P}<0.05 ;{ }^{* *} \mathrm{P}<0.01$.

T24 cells in the presence of Lv-miRNA-556-3p compared with untreated cells, whereas miRNA-556-3p inhibition markedly decreased the growth rate of BIU-87, 5637 and T24 cells in the presence of Lv-miRNA-556-3p-inhibition $(\mathrm{P}<0.05)$. No significant difference was found in cell proliferation between Lv-control cells and untreated cells $(\mathrm{P}>0.05)$. Collectively, these results indicated that enhanced miRNA-556-3p expression promoted $\mathrm{BC}$ cell proliferation in vitro.
Restored DAB2IP expression attenuates invasion, migration and colony formation of $B C$ cells. Published data showed that DAB2IP functions as a suppressor of tumorigenesis and metastasis of BC cells (34). We hypothesized that miRNA556-3p affects the biological behavior of $\mathrm{BC}$ cells by negatively regulating DAB2IP. To test this hypothesis, a 'rescue' experiment with Lv-miRNA-556-3p and Lv-DAB2IP was performed in vitro in BIU-87, 5637 and T24 cells. After $72 \mathrm{~h}$ of transfec- 
A

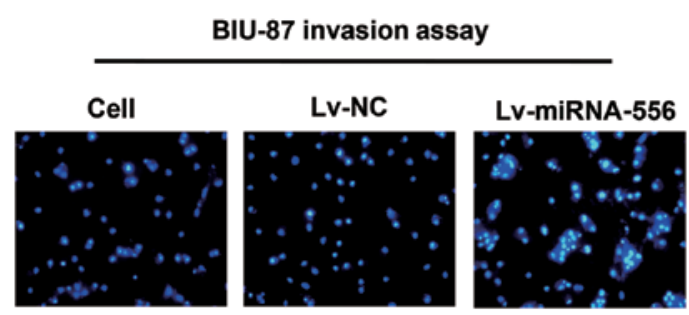

Lv-miRNA-556+Lv-DAB2IP Lv-miRNA-556-inhibition
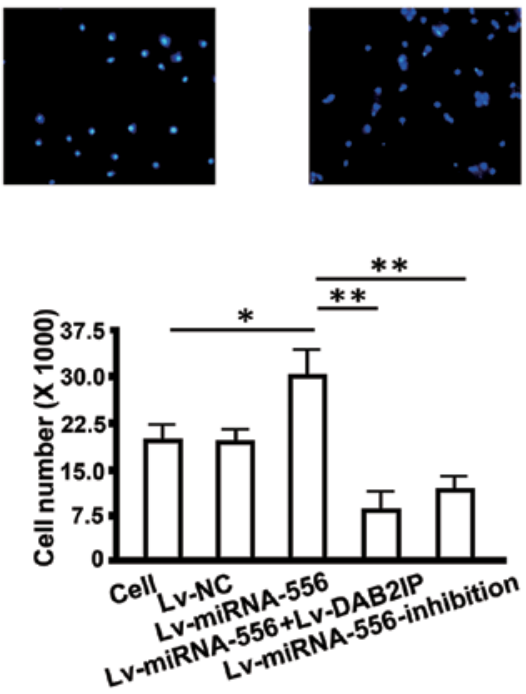

C

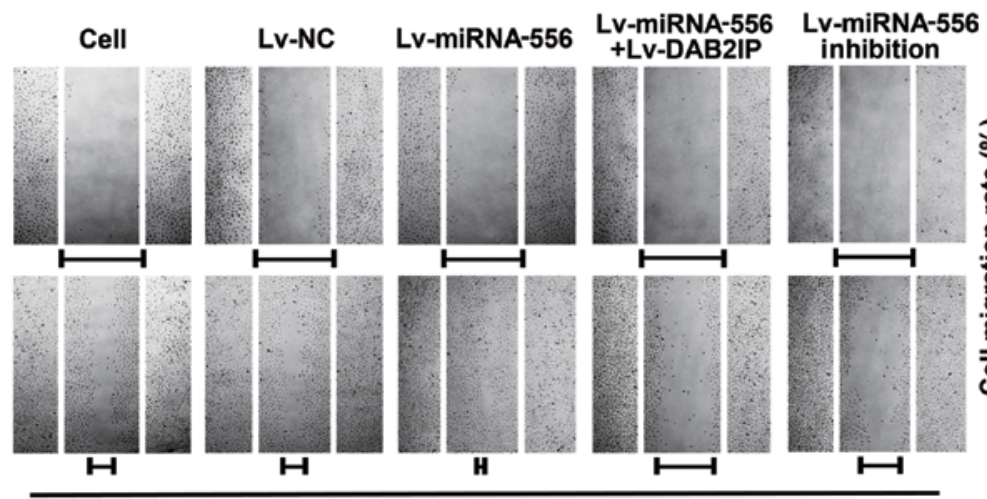

5637 Wound-healing Assay (Upper-Day 1; Lower- Day 3)
B

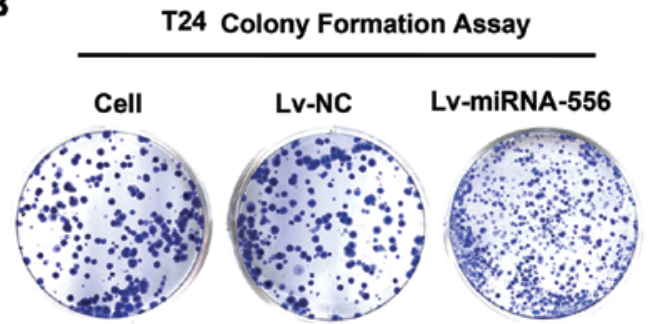

Lv-miRNA-556+Lv-DAB2IP Lv-miRNA-556-inhibition
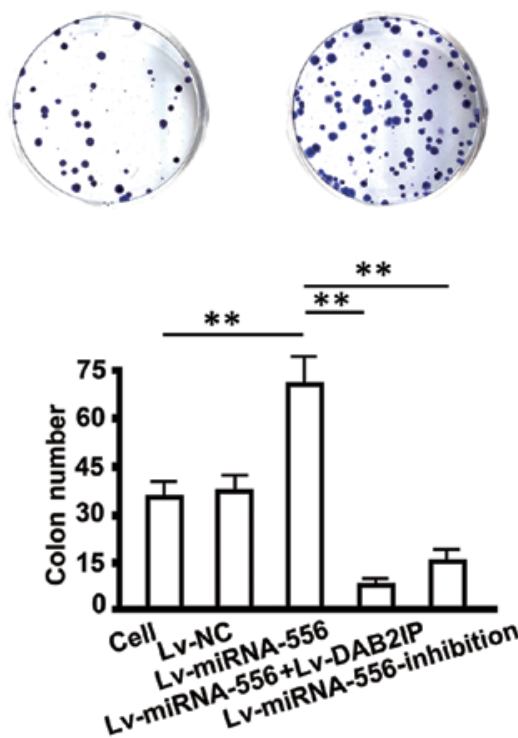

Figure 4. Promoted effect of miRNA-556-3p on invasion ability, migration ability and colony formation ability of BC cells. (A) Promoted effect of miRNA-556-3p on the invasion ability of BIU-87 cells was detected by Transwell assay. The invasive cells were counted under a microscope. (B) Representative results of colony formation of 5637 cells stably transfected with Lv-miRNA-556-3p or Lv-miRNA-556-3p-inhibition. (C) Effect of promotion of miRNA-556-3p on the migration capacity of T24 cells was detected by wound-healing assay. The measurement of the gap was taken under a microscope on day 1 and day 3 , respectively. The results represent data from at least three indepentent experiment expressed as mean $\pm \mathrm{SD}$. ${ }^{*} \mathrm{P}<0.05 ;{ }^{* *} \mathrm{P}<0.01$.

tion, BIU-87, T24 and 5637 cells were harvested for invasion, colony formation and migration assays, respectively. As shown in Fig. 4A, miRNA-556-3p overexpression significantly promoted invasion of BIU-87 cells invasion compared with untreated cells, whereas the number of invaded cells was obviously lower following transfection with Lv-DAB2IP.

Furthermore, cell invasion was significantly inhibited when Lv-miRNA-556-3p-inhibition was transfected into BIU-87 cells. A similar result was obtained in the colony formation assay with T24 cells. Transfection of Lv-miRNA-556-3p alone enhanced colony formation by $70 \%$. In contrast, cotransfection of Lv-miRNA-556-3p and Lv-DAB2IP markedly reduced colony formation by $50 \%$, and knockdown of miRNA-556-3p by Lv-miRNA-556-3p-inhibition also resulted in a $50 \%$ decrease of colonies. No difference in invasion, migration and colony formation assays was observed between in Lv-NC cells and untreated cells (Fig. 4B).

To measure the influence of restored DAB2IP expression on cell migration we performed a wound healing assay in 5637 cells. Cells that overexpressed miRNA-556-3p migrated to the wound more rapidly than untreated cells. Conversely, the motility of 5637 cells was markedly suppressed after treatment with Lv-DAB2IP, and introduction of Lv-miRNA-556-3pinhibition also exhibited an inhibitory effect on 5637 cell 
A
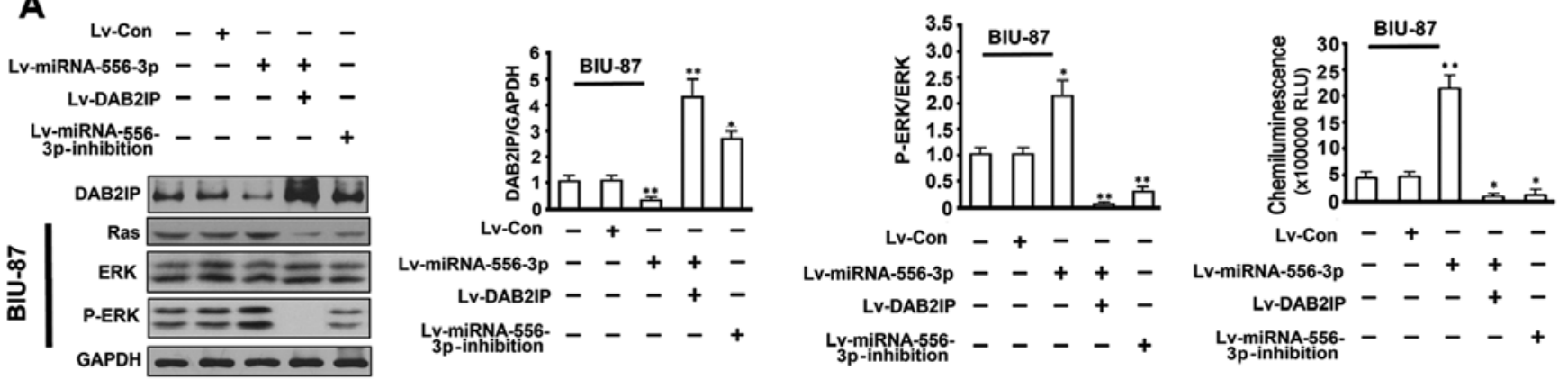

B
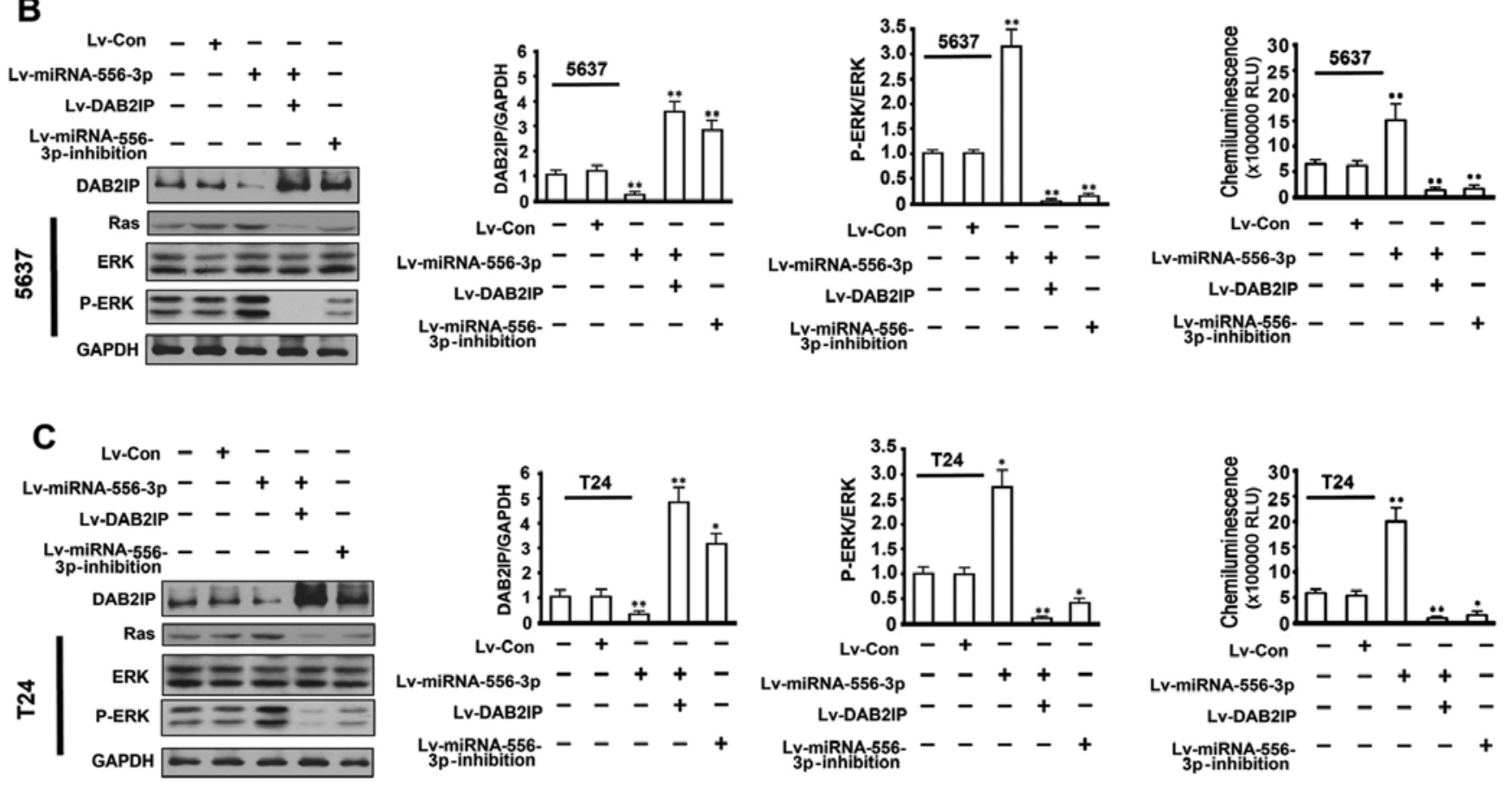

Western blotting assay

Ras GTPase ELISA

Figure 5. The suppression of DAB2IP expression mediated by miRNA-556-3p activates the Ras-ERK pathway. (A-C) The expression of DAB2IP, Ras and phosphorylated ERK1/2 (pERK1/2) in bladder cancer cell lines were detected using western blot analysis and the Ras GPTase activity in bladder cell lines were also detected by using Ras GTPase ELISA kit. The cell lines (BIU-87, 5637 and T24 cells) were transfected with lentivirus-mediated gene expression in the presence or absence of miRNA-556-3p or DAB2IP, respectively. The results represent data from at least three indepentent experiment expressed as mean \pm SD. ${ }^{*} \mathrm{P}<0.05 ;{ }^{* *} \mathrm{P}<0.01$.

migration (Fig. 4C). Therefore, miRNA-556-3p, functioned as a tumor promoter during tumorigenesis and metastasis of $\mathrm{BC}$ by directly targeting DAB2IP.

miRNA-556-3p-mediated DAB2IP suppression plays an oncogenic role by partially activating the Ras-ERK pathway. We next searched for molecular regulatory mechanisms that contributed to the above effects. Previous studies revealed that DAB2IP functions as a tumor suppressor in cancers through inhibition of the Ras-ERK pathway, a critical pathway for tumorigenesis $(35,36)$. In the present study, DAB2IP was identified as a target of miRNA-556-3p. Therefore, we wondered whether the miRNA-556-3p-mediated changes in biological behavior of $\mathrm{BC}$ cells are dependent on the Ras-ERK pathway. To address this issue, we examined expression of DAB2IP, Ras and phosphorylated ERK1/2 (pERK1/2), a central regulator of cell proliferation, in BIU-87, 5637 and T24 cells. As shown in Fig. 5, western blot analysis showed a decrease in DAB2IP protein and an increase in Ras and pERK1/2 compared with untreated cells when miRNA-556-3p expression was enhanced in BIU-87, 5637 and T24 cells by Lv-miRNA556-3p. Conversely, inhibition of miRNA-556-3p expression in BIU-87, 5637 and T24 cells by Lv-miRNA-556-3p-inhibition, resulted in significant upregulation of DAB2IP and downregulation of Ras and pERK1/2 proteins. Notably, in a rescue assay, cotransfection of Lv-miRNA-556-3p and Lv-DAB2IP not only markedly restored DAB2IP expression but also efficiently silenced Ras and pERK1/2 protein to a barely detectable level in BIU-87, 5637 and T24 cells. Transfection of Lv-control had no effect on DAB2IP, Ras and pERK1/2 protein expression compared with untreated cells. Ras GTPase ELISA assay showed that overexpression of miRNA-556-3p in BC cells could markedly increase Ras GTPase activity. Together, these results suggested that miRNA-556-3p-mediated DAB2IP 
suppression at least in part played an oncogenic role in $\mathrm{BC}$ cells by activating the Ras-ERK pathway.

\section{Discussion}

miRNAs are key factors in the regulation of cell proliferation, apoptosis and other important cellular processes (37). In past decades, miRNAs have been the focus of much research in oncology, and there are great expectations for their utility as cancer biomarkers and therapeutic targets $(38,39)$. Although many miRNAs are predicted to regulate target mRNAs and are dysregulated in their respective cancer types, to date, few studies have reported the expression and function of miRNAs targeting DAB2IP in bladder cancer. In the present study, we primarily focus on the identification of miRNAs targeting DAB2IP and validation of their expression and function in BC.

It is estimated that $30 \%$ of genes in the human genome are regulated by miRNAs (39). Therefore, identification of aberrantly expressed miRNAs is critical in the analysis of human oncogenesis. To complete the study's main aim of discovering and validating differentially expressed miRNAs targeting DAB2IP in BC, we applied TargetScan 6.1 for an initial overview to identify candidate miRNAs. qRT-PCR and luciferase reporter assays confirmed that DAB2IP was a direct target of miRNA-556-3p. To the best of our knowledge, miRNA-556-3p is a newly identified miRNA specific to DAB2IP in BC and no functional study results on miRNA-556-3p have previously been published. Identification of miRNA-556-3p offered a sound basis for further studies to determine its expression and biological function in BC. Our data revealed that, compared with controls, endogenous miRNA-556-3p expression was significantly upregulated in clinical samples of $\mathrm{BC}$ patients and BC cell lines, whereas DAB2IP expression was simultaneously downregulated.

Based on these findings, we speculated that miRNA-556-3p might function in as a tumor promoter in BC. As expected, gain or loss of function assays through transfection of Lv-miRNA-556-3p or Lv-miRNA-556-3p-inhibition indicated that enhancement of miRNA-556-3p expression could promote proliferation, invasion and migration, and colony formation of BC cells, whereas repression of miRNA-556-3p expression yielded opposite results. More importantly, a 'rescue' experiment with Lv-miRNA-556-3p and Lv-DAB2IP not only attenuated invasion, migration and colony formation of BC cells, but also reversed the tumor promotion effect induced by miRNA-556-3p. In fact, these results underline the great potential of miRNA-556-3p as an oncogene in the tumorigenesis and metastasis of BC though inhibition of DAB2IP. In fact, one previous study also demonstrated that the tumor overexpressive miR- $92 \mathrm{~b}$ promoted migration and invasion of BC cells, but had no effect on cell proliferation (15). Herein, we reported the function of a new important miRNA, miRNA556-3p not only promoted $\mathrm{BC}$ cells migration and invasion, but also promoted $\mathrm{BC}$ cells proliferation by negatively regulating DAB2IP expression. Many present studies have clearly indicated that one miRNA could control multiple oncogenes and antioncogenes, this may be the reason that miR-92b and miRNA-556-3p have the same targeted gene but play partly different roles in $\mathrm{BC}$ cells, thus further studies are needed to explore this.
The interaction between miRNA-556-3p and DAB2IP suggested important changes in molecular pathways in BC cells. In the present study, we observed a correlation of miRNA-556-3p with DAB2IP and the Ras-ERK pathway in $\mathrm{BC}$ cells. Western blot analysis showed a decrease in DAB2IP protein and an increase in Ras and pERK1/2 proteins in $\mathrm{BC}$ cells that overexpressed miRNA-556-3p, whereas introduction of Lv-miRNA-556-3p-inhibition in cells that underexpressed miRNA-556-3p cells produced opposite results. Intriguingly, restoration of DAB2IP in a 'rescue' assay efficiently silenced Ras and pERK1/2 protein to a barely detectable level in $\mathrm{BC}$ cells. Recent investigations have revealed that DAB2IP can modulate the activities of various pathways including Ras-Raf-ERK, ASK1-JNK and PI3K-Akt, providing potential mechanisms through which loss of DAB2IP can deregulate survival and apoptosis pathways, leading to tumor development (35). Specifically, DAB2IP inhibits the Ras pathway by directly binding to and inactivating H-Ras and R-Ras through its Ras GTPase activity (36). In this study, we detected the Ras GTPase activity in bladder cancer cell lines, and found that the overexpression of miRNA-556-3p in BC cells not only decreased DAB2IP expression, but also markedly increased Ras GTPase activity and ERK1/2 phosphorylation level. From all the above results, we propose that miRNA556-3p-mediated DAB2IP suppression promoted growth and metastasis of BC cells at least in part by activation of the Ras-ERK pathway.

There are some important limitations to the present study that need to be discussed. First, although miRNA556-3p expression was significantly upregulated in plasma and tissues from $\mathrm{BC}$ patients compared with controls, the number of clinical samples examined in this study was limited. Examination of additional clinical BC samples may provide more persuasive evidence supporting the relationship between miRNA-556-3p and DAB2IP. Second, a single target gene is not regulated by a single miRNA $(40,41)$. Our qRT-PCR analysis of clinical samples of BC patients showed that four upregulated miRNAs (miRNA-4725-5p, miRNA-556-3p, miRNA-4691-3p and miRNA-576-5p) might be involved in regulating DAB2IP expression (data not shown). Expression and function of these other miRNAs in $\mathrm{BC}$ should be investigated in future studies. Third, previous studies showed that miRNAs can be readily detected in bodily fluids including serum, plasma, saliva, urine and tears (42-45). The innate properties of miRNAs make them attractive as potential biomarkers. In this study, we determined the miRNA-556-3p expression level in plasma of BC patients and found that miRNA-556-3p plasma expression was enhanced in accordance with its high level in BC tissues. However, the relationship of miRNA-556-3p expression level with clinical features of $\mathrm{BC}$ patients, including diagnosis, therapy response, and prognosis, must be analyzed further to support the use of plasma miRNA-556-3p as a non-invasive marker for detection of bladder cancer.

Despite these limitations, we obtained sustainable evidence that miRNA-556-3p performs an oncogenic function in human $\mathrm{BC}$ cells via targeting DAB2IP. In conclusion, the present study provides novel insight into the role of miRNA-556-3p in human $\mathrm{BC}$ pathogenesis and suggests its potential application as a promising molecular target for $\mathrm{BC}$ therapy. 


\section{Acknowledgements}

The present study was supported by the National Science Foundation of China (no. 81372293 and 81241088 to Y.K.F.; no. 81273161 to K.J.F.), the Heilongjiang Province Science Funds for Distinguished Young Scientists (JC2015019 to Y.K.F.), the New Century Excellent Talents at Heilongjiang Province University (1254-NECT-023 to Y.K.F.; UNPYSCT2016113 and 12531736 to Y.M.P.), the Program for Innovation Research Team in Science and Technology at Mudanjiang Medical University, Department of Science and Technology of Heilongjiang Province of China (H201377 to P.S.).

\section{References}

1. Wu M, Dickinson SI, Wang X and Zhang J: Expression and function of SIRT6 in muscle invasive urothelial carcinoma of the bladder. Int J Clin Exp Pathol 7: 6504-6513, 2014.

2. Cornu JN, Neuzillet Y, Hervé JM, Yonneau L, Botto H and Lebret T: Patterns of local recurrence after radical cystectomy in a contemporary series of patients with muscle-invasive bladder cancer. World J Urol 30: 821-826, 2012.

3. Choi SY, Ryu JH, Chang IH, Kim TH, Myung SC, Moon YT, Kim KD and Kim JW: Predicting recurrence and progression of non-muscle-invasive bladder cancer in Korean patients: A comparison of the EORTC and CUETO models. Korean J Urol 55: 643-649, 2014

4. Vinall RL, Ripoll AZ, Wang S, Pan CX and deVere White RW: MiR-34a chemosensitizes bladder cancer cells to cisplatin treatment regardless of $\mathrm{p} 53-\mathrm{Rb}$ pathway status. Int J Cancer 130 2526-2538, 2012.

5. Tatarano S, Chiyomaru T, Kawakami K, Enokida H, Yoshino H, Hidaka H, Nohata N, Yamasaki T, Gotanda T, Tachiwada T, et al: Novel oncogenic function of mesoderm development candidate 1 and its regulation by MiR-574-3p in bladder cancer cell lines. Int J Oncol 40: 951-959, 2012.

6. Teply BA and Kim JJ: Systemic therapy for bladder cancer - a medical oncologist's perspective. J Solid Tumors 4: 25-35, 2014.

7. Dai X, North BJ and Inuzuka H: Negative regulation of DAB2IP by Akt and SCFFbw7 pathways. Oncotarget 5: 3307-3315, 2014.

8. Tsai Y-S, Lai C-L, Lai C-H, Chang KH, Wu K, Tseng SF, Fazli L, Gleave M, Xiao G, Gandee L, et al: The role of homeostatic regulation between tumor suppressor DAB2IP and oncogenic Skp2 in prostate cancer growth. Oncotarget 5: 6425-6436, 2014.

9. Kong Z, Xie D, Boike T, Raghavan P, Burma S, Chen DJ, Habib AA, Chakraborty A, Hsieh JT and Saha D: Downregulation of human DAB2IP gene expression in prostate cancer cells results in resistance to ionizing radiation. Cancer Res 70: 2829-2839, 2010.

10. Dote H, Toyooka S, Tsukuda K, Yano M, Ouchida M, Doihara H, Suzuki M, Chen H, Hsieh JT, Gazdar AF, et al: Aberrant promoter methylation in human DAB2 interactive protein (hDAB2IP) gene in breast cancer. Clin Cancer Res 10: 2082-2089, 2004

11. Yano M, Toyooka S, Tsukuda K, Dote H, Ouchida M, Hanabata T, Aoe M, Date H, Gazdar AF and Shimizu N: Aberrant promoter methylation of human DAB2 interactive protein (hDAB2IP) gene in lung cancers. Int J Cancer 113: 59-66, 2005.

12. Duan YF, Li DF, Liu YH, Mei P, Qin YX, Li LF, Lin QX and Li ZJ: Decreased expression of DAB2IP in pancreatic cancer with wild-type KRAS. Hepatobiliary Pancreat Dis Int 12: 204-209, 2013

13. Xie D, Gore C, Liu J, Pong RC, Mason R, Hao G, Long M, Kabbani W, Yu L, Zhang H, et al: Role of DAB2IP in modulating epithelial-to-mesenchymal transition and prostate cancer metastasis. Proc Natl Acad Sci USA 107: 2485-2490, 2010.

14. Min J, Zaslavsky A, Fedele G, McLaughlin SK, Reczek EE, De Raedt T, Guney I, Strochlic DE, Macconaill LE, Beroukhim R, et al: An oncogene-tumor suppressor cascade drives metastatic prostate cancer by coordinately activating Ras and nuclear factor-kappaB. Nat Med 16: 286-294, 2010.

15. Huang J, Wang B, Hui K, Zeng J, Fan J, Wang X, Hsieh JT, He D and $\mathrm{Wu} \mathrm{K}$ : miR-92b targets DAB2IP to promote EMT in bladder cancer migration and invasion. Oncol Rep 36: 1693-1701, 2016

16. Kutter C and Svoboda P: miRNA, siRNA, piRNA: Knowns of the unknown. RNA Biol 5: 181-188, 2008.

17. Bartels CL and Tsongalis GJ: MicroRNAs: Novel biomarkers for human cancer. Clin Chem 55: 623-631, 2009.
18. Croce CM: Causes and consequences of microRNA dysregulation in cancer. Nat Rev Genet 10: 704-714, 2009.

19. Fendler A, Stephan C, Yousef GM and Jung K: MicroRNAs as regulators of signal transduction in urological tumors. Clin Chem 57: 954-968, 2011.

20. Døssing KBV, Binderup T, Kaczkowski B, Jacobsen A, Rossing M, Winther O, Federspiel B, Knigge U, Kjær A and FriisHansen L: Down-regulation of miR-129-5p and the let-7 family in neuroendocrine tumors and metastases leads to up-regulation of their targets Egr1, G3bp1, Hmga2 and Bach1. Genes (Basel) 6: 1-21, 2014.

21. Du C, Lv Z, Cao L, Ding C, Gyabaah OA, Xie H, Zhou L, Wu J and Zheng S: MiR-126-3p suppresses tumor metastasis and angiogenesis of hepatocellular carcinoma by targeting LRP6 and PIK3R2. J Transl Med 12: 259, 2014.

22. Ujihira T, Ikeda K, Suzuki T, Yamaga R, Sato W, Horie-Inoue K, Shigekawa T, Osaki A, Saeki T, Okamoto K, et al: MicroRNA574-3p, identified by microRNA library-based functional screening, modulates tamoxifen response in breast cancer. Sci Rep 5: 7641, 2015.

23. Hu J, Cheng Y, Li Y, Jin Z, Pan Y, Liu G, Fu S, Zhang Y, Feng K and Feng Y: microRNA-128 plays a critical role in human non-small cell lung cancer tumourigenesis, angiogenesis and lymphangiogenesis by directly targeting vascular endothelial growth factor-C. Eur J Cancer 50: 2336-2350, 2014.

24. Itesako T, Seki N, Yoshino H, Chiyomaru T, Yamasaki T, Hidaka H, Yonezawa T, Nohata N, Kinoshita T, Nakagawa M, et al: The microRNA expression signature of bladder cancer by deep sequencing: The functional significance of the miR-195/497 cluster. PLoS One 9: e84311, 2014.

25. Feng Y, Liu J, Kang Y, He Y, Liang B, Yang P and Yu Z: miR-19a acts as an oncogenic microRNA and is up-regulated in bladder cancer. J Exp Clin Cancer Res 33: 67, 2014.

26. Xiu Y, Liu Z, Xia S, Jin C, Yin H, Zhao W and Wu Q: MicroRNA137 upregulation increases bladder cancer cell proliferation and invasion by targeting PAQR3. PLoS One 9: e109734, 2014.

27. Lin T, Dong W, Huang J, Pan Q, Fan X, Zhang C and Huang L: MicroRNA-143 as a tumor suppressor for bladder cancer. J Urol 181: 1372-1380, 2009.

28. Li S, Xu X, Xu X, Hu Z, Wu J, Zhu Y, Chen H, Mao Y, Lin Y, Luo J, et al: MicroRNA-490-5p inhibits proliferation of bladder cancer by targeting c-Fos. Biochem Biophys Res Commun 441: 976-981, 2013.

29. Pignot G, Cizeron-Clairac G, Vacher S, Susini A, Tozlu S, Vieillefond A, Zerbib M, Lidereau R, Debre B, AmsellemOuazana $\mathrm{D}$, et al: microRNA expression profile in a large series of bladder tumors: Identification of a 3-miRNA signature associated with aggressiveness of muscle-invasive bladder cancer. Int J Cancer 132: 2479-2491, 2013

30. Liang Z, Li S, Xu X, Xu X, Wang X, Wu J, Zhu Y, Hu Z, Lin Y, Mao Y, et al: MicroRNA-576-3p inhibits proliferation in bladder cancer cells by targeting cyclin D1. Mol Cells 38: 130-137, 2015.

31. Ichimi T, Enokida H, Okuno Y, Kunimoto R, Chiyomaru T, Kawamoto K, Kawahara K, Toki K, Kawakami K, Nishiyama K, et al: Identification of novel microRNA targets based on microRNA signatures in bladder cancer. Int J Cancer 125: 345-352, 2009.

32. Feng Y, Hu J, Ma J, Feng K, Zhang X, Yang S, Wang W, Zhang J and Zhang Y: RNAi-mediated silencing of VEGF-C inhibits non-small cell lung cancer progression by simultaneously down-regulating the CXCR4, CCR7, VEGFR-2 and VEGFR-3dependent axes-induced ERK, p38 and AKT signalling pathways. Eur J Cancer 47: 2353-2363, 2011.

33. Ronchetti S, Nocentini G, Giunchi L, Bartoli A, Moraca R, Riccardi C and Migliorati G: Short-term dexamethasone treatment modulates the expression of the murine TCR zeta gene locus. Cell Immunol 178: 124-131, 1997.

34. Shen YJ, Kong ZL, Wan FN, Wang HK, Bian XJ, Gan HL, Wang CF and Ye DW: Downregulation of DAB2IP results in cell proliferation and invasion and contributes to unfavorable outcomes in bladder cancer. Cancer Sci 105: 704-712, 2014.

35. Zhang R, He X, Liu W, Lu M, Hsieh JT and Min W: AIP1 mediates TNF-alpha-induced ASK1 activation by facilitating dissociation of ASK1 from its inhibitor 14-3-3. J Clin Invest 111: 1933-1943, 2003 
36. Xie D, Gore C, Zhou J, Pong RC, Zhang H, Yu L, Vessella RL, Min W and Hsieh JT: DAB2IP coordinates both PI3K-Akt and ASK1 pathways for cell survival and apoptosis. Proc Natl Acad Sci USA 106: 19878-19883, 2009.

37. Chekulaeva M and Filipowicz W: Mechanisms of miRNAmediated post-transcriptional regulation in animal cells. Curr Opin Cell Biol 21: 452-460, 2009.

38. Ratert N, Meyer HA, Jung M, Lioudmer P, Mollenkopf HJ, Wagner I, Miller K, Kilic E, Erbersdobler A, Weikert S, et al: miRNA profiling identifies candidate mirnas for bladder cancer diagnosis and clinical outcome. J Mol Diagn 15: 695-705, 2013.

39. Baffa R, Fassan M, Volinia S, O'Hara B, Liu CG, Palazzo JP Gardiman M, Rugge M, Gomella LG, Croce CM, et al: MicroRNA expression profiling of human metastatic cancers identifies cancer gene targets. J Pathol 219: 214-221, 2009.
40. Cho WCS: OncomiRs: The discovery and progress of microRNAs in cancers. Mol Cancer 6: 60, 2007.

41. Esquela-Kerscher A and Slack FJ: Oncomirs - microRNAs with a role in cancer. Nat Rev Cancer 6: 259-269, 2006.

42. Geng Q, Fan T, Zhang B, Wang W, Xu Y and Hu H: Five microRNAs in plasma as novel biomarkers for screening of early-stage non-small cell lung cancer. Respir Res 15: 149, 2014.

43. Kosaka N, Iguchi H and Ochiya T: Circulating microRNA in body fluid: A new potential biomarker for cancer diagnosis and prognosis. Cancer Sci 101: 2087-2092, 2010.

44. Cortez MA, Bueso-Ramos C, Ferdin J, Lopez-Berestein G, Sood AK and Calin GA: MicroRNAs in body fluids - the mix of hormones and biomarkers. Nat Rev Clin Oncol 8: 467-477, 2011.

45. Szeto CC: Urine miRNA in nephrotic syndrome. Clin Chim Acta 436: 308-313, 2014. 